\title{
SCIENCE IN THE MODERN WORLD
}

TN a paper entitled "The Task before Us", read 1 before the American Academy of Arts and Sciences at Boston on April 14*, Dr. P. W. Bridgman examined the philosophy of the founding fathers of American democracy in the light of the scientific thought of this century. He suggested that we have forgotten to regard democracy as a growing thing, evolving to meet our changing conceptions of ourselves and our place in Nature. Anti-intellectualism, he said, might be a symptom of something more deep-seated, and the emphasis on a return to humanistic attitudes requires a revitalization of the humanities themselves in the light of our recent intellectual experiences. We need to assimilate into our whole intellectual outlook, and in particular into our relation to social problems, the lessons implicit in scientific experience. Considering first the changes in intellectual attitude forced on us by such experience, Dr. Bridgman said that a necessary mark of a liberally educated man is the realization that our thinking and intellectual processes in general cannot be taken for granted. When we think, we use intellectual tools, and these tools have properties and limitations. In particular, recent experience shows that when we push the application of many of our concepts into new fields, limitations appear which we could not have anticipated from anything in our former more limited common-sense experience. We have now come to expect that a concept inherited from our ancestors will not be applicable when pushed into fields hitherto unentered. Analogy suggests that the presumption is that such concepts as human rights or duties or responsibilities require modification when the environment in which they $\operatorname{aros} \theta$ is altered, as it now is, by technological advances that bring all men over the whole world into immediate mutal relations.

Dr. Bridgman suggested that it is not a common idea that there are still regions in which the man of science is groping his way and knows that he has not yet found the answers. Failure to realize this is one reason for the impatience of people with the scientific

* The Task before Us. By P. W. Bridgman. Proc. Amer. Acad. Arts Sci., 83, No. 3, ii $+95-112$ (1954). 50 cents. point of view and for the urge to return to a moro humanistic outlook. Among such unsolved problems, Dr. Bridgman gave as examples that of the 'observer' in quantum physies and the growing concern with the basic problem of what sort of thing a brain is. One of the results which is beginning to emerge from cybernetics is a realization of the extent to which our conscious activities have to be selected from the overwhelming number of potentialities. 'The problem becomes not to find the absolute truth but to find how to do the best we can with what we have. Moreover, in psychology the new approach to the nature of perception is forcing on us the simple realization that all our conscious thinking is done in terms of perceptions, and we are now asking whether in the domain of ordinary experience the mould of space and time into which perception pours our world is a good mould. Dr. Bridgman believes that our task is to-find the present status, in the light of all the insights now available to us, of such fundamental concepts as human rights, freedom, equality, duty and justice, and in the light of these insights to strengthen if possible, or to revise if necessary, the conceptual foundation of our social and political system. 'This task will demand a long campaign of education and the slow development of new intellectual techniques by a process involving much trial and error.

Reviewing more concrete aspects of the situation, Dr. Bridgman believes that analysis of the processes in a democratic society will in this way lead us to a society in which tho relation between society and the individual is based on mutual advantage and service. Only exceptionally will it involve honouring minimum claims on the community whether or not any return is made; but it will also involve a revision in the philosophy underlying the system of taxation. Finally, it will place emphasis on two virtues : the repugnance of the individual to exercise force against his neighbour for his own advantage, and the imagination that can sense the significance of the simple underlying processes and relations so easily lost to sight under the complexities of modern lifeor, in other words, intelligence.

\section{THE OIL INDUSTRY}

$\mathrm{T}$ HE oil industry is one which could be said to be less than a hundred years old, or more than two thousand.

It seems probable that it was an ingenious Chinaman who first drilled a hole into the earth's surface. He was in search of salt water and natural gas which he could use as the fuel to evaporate the water to yield salt. In the process he or his successors at times bored down to three thousand feet and incidentally struck oil. They had no use for the oil except as a lubricant (Esso Magazine, 3, No. 11; Spring, 1954).

The rig these Chinese devised is basically not unlike the cable rig used to-day; it sometimes took them ten years to drill a deep hole with their rigs.

Drake used the cable rig method when drilling the world's first commercial oil well in 1859. It was fortunate that he made his attempt in Pennsylvania rather than in Texas, because when the drillers got to
Texas they encountered softer rock formations in which the simple cable rig was useless; the sides of the holes caved in as fast as the bits pounded through. As a result the rotary rig came into being; with this a hole is drilled through rock instead of being pounded through. A length of piping with a 'bit' on its end is gripped and rotated like a carpenter's drill. Mud, forced down the pipe, comes to the surface again in the space between pipe and hole, thus sealing off loose formations as the hole is drilled and bringing the cuttings to the surface. Two-thirds of wells sunk to-day are drilled by rotary rigs.

The drill pipe has greater precision than the cable for deeper holes; it also goes down straighter. This is important to-day, when wells are being drilled deeper every year.

During the Second World War there was not enough easily located shallow oil to keep industry and machines operating. New sources had to be 